\title{
APONTAMENTOS PARA UMA TÊNUE URDIDURA. UM PALIMPSESTO DE TEORIAS E SUAS IMBRICAÇÕES NA ARQUEOLOGIA
}

\author{
José Alberione dos Reis*
}

\begin{abstract}
"Em uma palavra, os raios de luz que as estrelas nos enviam não nos chegam instantaneamente, e sim empregando um certo tempo em transpor a distância de separação, não nos mostrando as estrelas tal qual são agora, mas tal qual eram por ocasião em que partiram esses raios de luz transmissores do respectivo aspecto. Aí está uma surpreendente transformação do passado em presente. Para o astro observado, é o que já se passou, o já desaparecido; para o observador, é o presente, o atual. O passado do astro é rigorosa e positivamente o presente do observador"
\end{abstract}

(Flammarion [1866] (1979:36).

\section{Preparando}

A tela da tecelagem é a Arqueologia. A trama e a urdidura dos fazeres deste texto serão trançadas pela teoria no que se vai tecendo na Arqueologia. A teoria como referência a dois eventos internacionais que a tiveram como tema.

Neste texto proponho um entrelaçar de assuntos sobre teoria em Arqueologia que compuseram duas reuniões internacionais. Vou, portanto, comentar alguns tópicos desses eventos.

Que eventos são esses? Trata-se de duas reuniões internacionais de teoria arqueológica. A primeira aconteceu em 1998, na cidade de Vitória/ ES. ' Segundo seus organizadores (Funari et all. 1999), a tônica da reunião teve sua importância por provocar um debate sobre questões teóricas, algo quase inédito na Arqueologia brasileira. Tendo

(*) Doutorando do Programa de Pós-Graduação em História da Universidade de Campinas, UNICAMP, SP. Bolsista da FAPESP.

(1) I Reunião Internacional de Teoria Arqueológica na América do Sul - Vitória - Espírito Santo/Brasil, 1998. Neste texto será sempre referendada pela seguinte sigla: IRITAAS. Os artigos apresentados nesta reunião já foram publicados (Fleming 1999). como ancoragem a teoria arqueológica, os assuntos discutidos na I RITAAS foram assim agrupados: métodos, história da arqueologia latino-americana, etnicidade, cultura material e patrimônio. A segunda ocorreu em 2000, na cidade de Olavarría/Argentina. ${ }^{2} \mathrm{Na} 2^{2}$ RITAAS o destaque teórico foi para a Arqueologia Pré-histórica e os temas debatidos foram os seguintes: tendências em Arqueologia evolutiva, feminismo e gênero, etnicidade, multivocalidade, arqueologias regionais, história da arqueologia da América do Sul, construção e desconstrução do registro arqueológico, patrimônio cultural e educação, tendências contemporâneas na Arqueologia sul-americana. Para as duas reuniões, ${ }^{3}$ alguns assuntos foram comuns e outros, porém, apontando para caminhos bastante peculiares.

Assim, o meu intuito nesse texto é o comentário e discussão de alguns dos temas acima enuncia-

(2) $2^{a}$ Reunión Internacional de Teoría Arqueológica en América del Sur - Olavarría - Província de Buenos Aires Argentina, de 4 a 7 de outubro de 2000 . Neste texto será referendada pela seguinte sigla: ${ }^{2}$ RITAAS. Os comentários sobre esta reunião advirão de material inédito, já que os artigos apresentados ainda não foram publicados. (3) Este ano, entre 20/21 de setembro, aconteceu a $3^{a}$ Reunión Internacional de Teoría Arqueológica en América del Sur, em Bogotá/Colômbia. 
dos e os cruzamentos destes com as propostas teóricas neles incluídas. Comentários e cruzamentos sendo aqui propostos como um lugar crítico em relação aos domínios já possíveis das condições de possibilidade da teoria na Arqueologia brasileira. Tecerei, também, alguns questionamentos em relação ao que se possa entender por inter e transdisciplinaridade em relação ao lugar da teoria na Arqueologia brasileira.

\section{Enlaçando}

Na tessitura da glosa, seguem-se alguns textos escolhidos a partir do que foi trabalhado nas apresentações que compuseram o total das duas reuniões teóricas de Arqueologia. O título em destaque é o que foi dado por cada autor do texto glosado. O critério de seleção dos textos das duas reuniōes internacionais apontou para a escolha de quatro temas que destacaram o lugar da teoria em suas elaborações: teorizando teorias; Arqueologia Histórica e teorias; Arqueologia Sul-americana e teorias; Patrimônio e cultura material, teorizações.

\subsection{Teorizando teorias}

Este tópico pode ser apresentado como o núcleo temático para se efetuar discussões sobre teoria em Arqueologia. São textos cujo objetivo precípuo consiste em teorizar sobre teorias específicas do fazer arqueológico e suas imbricações com os mais variados campos do conhecimento, entrelaçados e comprometidos com aquele fazer.

\section{"A materialidade e o social"}

Este texto caracteriza a Arqueologia como sendo típica da modernidade. Para Thomas (1999) a era moderna com a revolução científica oriunda do Iluminismo não descobriu e, sim, construiu um pensamento moderno sobre a ordem da natureza. Estas possíveis descobertas da Ciência moderna se presentificaram em construções de campos do conhecimento, dentre eles o arqueológico.
A Arqueologia - estudo da cultura material - a tem enfocado como manifestação de normas e valores de uma sociedade tal ou como produto e reflexo do mundo social. Estas posições trazem sérios problemas. Para Thomas (1999) os vestígios assim estudados são caracterizados como pálidos restos de grupos já desaparecidos. Além disso, sabe-se que muitas comunidades não têm a menor distinção ou esquemas duais entre o que seja cultura/natureza, por exemplo. É preciso encarar a materialidade da cultura como oriunda de práticas sociais nas quais as pessoas fazem, agem em relações e se engajam em condutas sociais. $O$ destaque para o estudo da cultura material como campo do social provoca um novo enfoque que sai do estudo de entidades para o de relações.

Neste jogo, Thomas (1999) traz a questão do poder em termos de vida social, aproximando-se do pensamento de Foucault. Para este, poder é rede de relações não criadas mas produzidas pelas pessoas. O poder restringindo e também facilitando as ações sociais e finalizando em efeitos sobre o social. A cultura material como um destes efeitos do poder. As pessoas ao ocuparem diferentes espaços na rede do poder produzirão diferentes contextos materiais, diferentes mundos materializados, diferentes lugares. "A cultura material não é, portanto, um simples produto da sociedade, ela é integral à sociedade. Segue-se que materiais que restam do passado, são mais que testemunhos de uma entidade extinta: são uma parte daquela entidade que ainda está aqui conosco presente " (op. cit.: 18).

Concluindo, o autor enfatiza que a tarefa interpretativa do arqueólogo diz respeito a artefatos implicados em relações criadas e produzidas na vida cotidiana. "... estou sugerindo que a apreensão do mundo material é um fenômeno social. Como as coisas são materializadas, dependem da linguagem das concepções, da experiência e das relações de poder que convergem em uma experiência particular" (op. cit.: 19).

\section{"Por que há cultura material ao invés de nada uma questão esquecida da Arqueologia"}

Este é um ensaio sobre questões filosóficas. Pode causar frisson trazer Filosofia para as malhas da Arqueologia. A pergunta do título é sobre a 
óbvia constatação de que a cultura material existe, está ali sob a terra para ser escavada e interpretada. Pergunta Karlsson (1999) sobre o que sabemos de sua Existência, com um "e" maiúsculo. Vai buscar em Heidegger o conceito de Existência "como o processo que faz tudo que é manifesto, que o faz aparecer" (op. cit.: 21).

Acentuando a importância para a Arqueologia, em relação ao estudo da cultura material, de buscar entendimento da diferença ontológica entre Existência como História e o pensamento humano, Karlsson (1999) tece críticas tanto ao processualismo como ao pós-processualismo. Ambas teorias concebem a Existência do passado através da mera visibilidade e manifestação dos vestígios como construções sociológicas do presente ou postulados de metodologias científicas. Para o autor, ambas as escolas “.... nunca respondem às questões que emanam da Existência destas existências" (op. cit.: 24).

Por estarem centradas num "antropocentrismo pós-socrático" (op. cit.: 24), diversas linhas teóricas na arqueologia contemporânea não dão conta de responder estas questões de Existência/ existência. Para tal, o autor propõe uma Arqueologia Contemplativa de inspiração heideggeriana. Esta proposta visa provocar nos arqueólogos um remexer nas suas passividades e chamá-los a pensar sobre a cultura material, seja do passado ou presente, não como produto de significados finais em si, mas “... ela (cultura material) ou melhor a sua Existência é ainda a origem do que os arqueólogos conhecem e fazem" (op. cit.: 26). Esta Arqueologia Contemplativa busca um pluralismo teórico para se trabalhar os vestígios materiais nas mais diferentes abordagens $e$ interpretações teóricas. Tem por escopo provocar amplas reflexões filosóficas num pensar múltiplo que guia e funda teoria na Arqueologia.

Até agora, nós arqueólogos, presos no antropocentrismo pós-socrático, temos argumentado somente sobre o status ontológico das existências, enquanto não temos reconhecido a diferença ontológica e a unidade entre Existência (como História) e pensamento humano que precede esta argumentação secundária. Nem temos sido cientes do fato que é a Existência (como História) que deixa os fenômenos (a cultura material) tornarem-se presentes para nós (op. cit.: 28).

\section{“As geociências e suas implicações em teoria e métodos arqueológicos"}

Aqui um aporte a um campo das chamadas ciências duras, o das Geociências. $\mathrm{O}$ empenho do autor é para chamar a atenção de que, mesmo tendo como objeto as ações humanas, o campo da materialidade da Arqueologia está diretamente ligado à terra. Assim imbricam-se, devido à circunstância de que os vestígios humanos estarão sempre depositados em ambientes da natureza, objetos da Geologia e da Geografia.

Para Araujo (1999), a Arqueologia nasce envolvida com problemas geológicos que associavam vestígios humanos, estratigrafia e cronologia. A partir de fins do século XIX e início do século XX, vai ocorrer um distanciamento entre a Geologia e a Arqueologia. Esta passa a receber maiores influências da Geografia Humana e da Etnologia. A partir dos anos de 1960, prepondera a influência da "Nova Arqueologia" apontando para uma pesquisa acurada sobre os processos de formação do registro arqueológico além dos estudos comportamentais, destacando-se aqui os trabalhos de Michael Schiffer. Este alertava para a necessidade de compreensão das transformações por que passava o registro arqueológico independentes, às vezes, dos registros referentes às ações humanas. Neste sentido, os arqueólogos deveriam se preocupar em entender a importância de estudos relacionados com processos físico-químicos que atuavam na construção do registro arqueológico, conjugados ou não com a presença humana. Desta vertente vai se desenvolver a Geoarqueologia cuja importância para Araujo (1999) diz respeito à constatação de que “...todos os sítios arqueológicos são potencialmente um problema geoarqueológico" (op. cit.: 40).

Araujo (1999) pergunta, então, sobre o que poderia concatenar teoria em Arqueologia a estas peculiaridades do registro arqueológico oriundas da Geoarqueologia. Apontando as contribuições de Clarke, Sullivan, Binford e Schiffer, Araujo propõe um conjunto de cinco modelos teóricos que contemplariam questões envolvendo a Arqueologia e a Geoarqueologia: Teoria Explanatória, Teoria Formativa, Teoria de Recuperação ou Registro, Teoria Formal ou Sistemática e Teoria Inferencial. Salientando a fundamental importância para a Arqueologia de buscar fundamentação em corpos teóricos, como os acima apontados e construídos pelo autor, este conclui que: "É necessário, portanto, 
investir no conhecimento do registro arqueológico porque nossas perguntas não são as mesmas formuladas por profissionais das Geociências. (...). Arqueologia é simplesmente Arqueologia" (op. cit.: 44).

\section{“Passos preliminares para a construção de um modelo sistêmico-processual-dialético"}

Este texto pretende expor uma possibilidade de construção de um modelo teórico-antropológico com aplicabilidade ao registro arqueológico. A partir dos conceitos intitulados neste trabalho, aponta Aguirre (2000) que estes se ancoram na teoria geral dos sistemas, em enfoque processualistas, no materialismo dialético, na teoria social latinoamericana e nos pressupostos processuaiscognitivos de Renfrew e Bahn.

Para Aguirre (2000), este modelo é Sistêmico por que considera sistema como tudo aquilo por onde circula matéria, energia e informação; é Processual por estudar processos contínuos ou descontínuos que operaram na história humana; é Dialético pelo uso dos conceitos de infra e superestrutura do marxismo que compõem amplamente os sistemas culturais humanos. Esta dialética, estudada a partir do registro arqueológico, visa avaliar diferenças intra e intersocietais que ocorrem no processo biosocial e/ou biocultural no âmbito das ações humanas.

O tipo concreto de perguntas que o modelo trata de responder são aquelas referidas a quais níveis de energia as sociedades humanas atuais, históricas e pré-históricas, disponibilizam e têm disponibilizado insumos no conjunto de suas atividades, como estas estão e têm estado distribuídas, que causas motivam estes níveis de insumos e de distribuição e por que os mesmos têm variado ou se mantido ao largo do tempo e/ou do espaço (op. cit.: 96).

Concluindo, salienta Aguirre (2000) que este modelo se propõe avaliar e avançar sobre aspectos que já têm feito composição em programas processuais, tais como: os tecnológicos, os ecológicos e os econômicos. $\mathrm{O}$ modelo apresentado visa uma superação destes programas processuais em termos de seus aspectos meramente funcionais.

\section{"Teorias para o conhecimento ou teorias para a "fixação de crenças""}

\section{Consens (2000) alerta para as profundas} mudanças ocorridas nas concepções do que seja Arqueologia na América do Sul, nos últimos vinte anos. Tais mudanças advieram, de um lado, pelo intenso aporte de equipamentos e tecnologias sofisticadas e, de outro, pela circularidade de campos do conhecimento que se propõem entender e interpretar vestígios com a utilização das mais variadas teorias e metodologias. Muito do que vem provocando mudanças advém do âmbito conceitual, o que leva a uma ampliação de aproximações para o entendimento do passado humano. Salienta Consens (2000) sobre os tantos "ismos" que se seguem como sobrenomes da Arqueologia. Segundo o autor, aqueles "... incluem em alguns casos (muito mais do que seria desejável), mais busca de poder pessoal e institucional do que conhecimento" (op. cit.: 98).

Para Consens (2000) o certo é que na América do Sul o que se entende por Arqueologia mudou radicalmente. Para uma sobrevivência acadêmica é preciso entender e aceitar estas mudanças, modificando práticas e discursos, caso contrário os arqueólogos sul-americanos perecerão intelectualmente. Um fator importante e provocador da mudança diz respeito a uma massiva investida de informações arqueológicas oriundas de países de língua inglesa. Junto com elas vieram métodos, procedimentos e técnicas até então desconhecidos. "O terrível não foi que utilizamos esses equipamentos e técnicas para transgredi-los ou derrubá-los, senão que muitos foram utilizados e aplicados sem nenhuma crítica ou avaliação de sua factibilidade " (op. cit.: 99).

A perturbação e o desconforto desta mudança também advém de que hoje há um desafio plenamente instalado no trabalho arqueológico que consiste na abismal diferença entre a apreensão empírica dos vestígios nos sítios escavados e uma Arqueologia que prioriza formulações conceituais sobre tais vestígios. Para Consens (2000), marcos teóricos são imprescindíveis no sentido de gerar, transformar e trabalhar os vestígios em meta-dados.

Tal desafio advém de uma situação concreta e intensa para a atual Arqueologia: de um lado aquela que resiste em velhos paradigmas e aquela que se abre aos novos, de forma às vezes acrítica e até doutrinária. Assim conclui Consens (2000:101): 
Porque, além dos discursos desencontrados e esquizofrênicos, condenamos as jovens gerações de arqueólogos a dissuadir seus esforços e expectativas que não necessariamente estão limitadas em aspectos econômicos e institucionais. Condenamos com um não à criação e ao desenvolvimento, com a fixação de novos ritos e novas fórmulas canonizadas. Ao culto curricular da fixação de crenças.

\section{"Anti-Hodder: diatribe contra as veleidades pós-modernistas no pós-processualismo de Ian Hodder"}

Uma contundente arremetida. Uma leitura crítica, mesmo que especulativa, sobre determinados argumentos que se naturalizaram na Arqueologia contemporânea da América do Sul, a partir de uma incorreta prática acadêmica e de uma dependência intelectual, de acordo com Velandia (2000) e por ele denominada de Grande Teoria. A autor refere-se à forma como certas arqueologias fazem uso, sem acuradas investigações e críticas, de propostas teóricas produzidas na metrópole e, em especial, as advindas de Hodder e suas resoluções pós-processualistas.

Para Velandia (2000), Hodder, a partir de uma visão historicista do objeto da Arqueologia, conseguiu explicitar as inconsistências de Binford no sentido de que este não superou sua antipatia pela História e pela historicidade dos processos de deposição inculcados no registro arqueológico.

Mas o autor para aí. Sua diatribe rancorosa é assim assumida: "Com o argumento de Hodder de que o processo de interpretação consiste na ....adscrição de significados... aos significantes do registro arqueológico, basta simplesmente ser um novelista com algo de imaginação, como certo best-seller da moda "(op. cit.: 134).

\section{"A construção do passado em Arqueologia"}

Partindo de algumas construções teóricas gerais da modernidade e da pós-modernidade, Zarankin (2000) propõe discutir duas correntes teóricas em Arqueologia - processualismo e pósprocessualismo - e suas diferentes abordagens sobre como se entende e constrói o passado.
O passado, a partir do pensamento moderno, se filia ao processualismo que advoga pela objetividade da pesquisa, pela cientificidade da Arqueologia, e por fundamentação em modelos bastante influenciados por filósofos da ciência, dentre eles Carl Hempel. Aqui os dados são independentes das teorias assumidas e é possível o conhecimento de um mundo objetivo a partir da ciência e seus métodos.

O pensamento pós-moderno e sua construção do passado em Arqueologia são abraçados pelo pós-processualismo. Amplas influências são absorvidas de filosofias anti-essencialistas ou nominalistas. A Arqueologia é encarada como prática assentada no marco do sistema capitalista, reapropriando e resignificando passado em função de interesses do presente. Existe um consenso de que a Arqueologia produz reconstruções subjetivas do passado, não existindo, portanto, um passado único ou verdadeiro mas vários passados construídos a partir de diferentes lugares, posições, olhares, discursos dos pesquisadores. Aqui o Arqueólogo é ativo e político na sua ação pesquisadora. Conclui assim Zarankin (2000:105): "Como toda a interpretação, o trabalho do arqueólogo é uma visão a mais que varia de profissional a profissional e de época a época. Desta forma as interpretações estão em um contínuo fluxo de transformação e mudança".

\subsection{Arqueologia Histórica e teorias}

Discorre-se agora sobre textos que estão envolvidos em contextos no âmbito da Arqueologia Histórica. São estudos de caso que imbricam, a partir de uma transdisciplinaridade para a especificidade do fazer arqueológico. Teorias que discutem relações entre a arqueologia e a teoria da rede, modelos arquitetônicos, e o capitalismo.

\section{"A teoria da rede e a Arqueologia da História moderna"}

Quais são as possibilidades e potencialidades da teoria da rede para as interpretações nos trabalho de Arqueologia Histórica? O texto de Orser (1999) traz como propósito responder esta questão. Tendo como ponto de partida a Antropologia, Sociologia e Geografia contemporâneas, a 
teoria da rede fundamenta-se no princípio de que homens e mulheres atuam socialmente imbricados em inter-relações que podem ser construídas como uma teia, uma rede. Homens e Mulheres produzindo e reproduzindo a vida social interligada como redes, como teias. Para Orser (1999), questionando o que ele denomina de "ponto de vista culturalista" este proporia explicações e interpretação simplistas de situações históricas complexas e esconderia relações sociais em mutação e historicidades. Contrapondo sua crítica, Orser (1999:89) apresenta a abordagem da teoria da rede como sendo aquela que "... rejeita de maneira franca a posição culturalista e propõe, em seu lugar, que paisagens sejam compreendidas como criações conscientes, baseadas não estritamente na cultura mas nas interações e associações de agentes masculinos e femininos."

Para que a teoria de rede tenha utilidade para a Arqueologia Histórica é preciso um desenvolvimento de quadros interpretativos que tenham relevância e ligação com os pressupostos desta teoria. Partindo da constatação de que o uso da informação textual tem sido como que definidora da peculiaridade da pesquisa em Arqueologia Histórica, Orser (1999) apresenta alguns quadros interpretativos como fundamentais para uso da abordagem da teoria da rede: num dado local sócio-histórico a evidenciação de relações em atividade; relações de ser humano para com ser humano e destes para com o ambiente em termos, ao mesmo tempo, sociais e espaciais; relações capitalistas nas quais se pressupõe relações de poder; identificação de lugares e espaços construídos e vividos por seres humanos; a espacialidade como expressão ideológica da ação humana sobre a terra.

Trazendo, numa breve apresentação esquemática, o caso do quilombo de Palmares, Orser (1999) demonstra como é possível a aplicação para a Arqueologia Histórica da abordagem da teoria de rede. Enfatizando a importância e o potencial desta teoria, assim aponta Orser (1999:93-94): "A presença do registro escrito e de outras fontes de informação oral ou escrita, torna a análise de rede consideravelmente mais interessante para os estudiosos da Arqueologia Histórica (...). Sem dúvida, as vantagens proporcionadas pela presença de informação textual dá uma enorme potencialidade à aplicação da análise de rede na Arqueologia Histórica"

\section{"Arqueología de la Arquitectura: another brick in the wall"}

Relações sociais construídas materialmente; a Arquitetura como criação de uma paisagem cultural humana; os objetos materiais produzidos humanamente como portadores e geradores de significados; a cultura material como uma dimensão ativa e ideológica dentro de um determinado sistema cultural assim como as subjetividades nela contidas e geradas, são os pressupostos que norteiam o trabalho de Zarankin (1999).

Partindo de que ainda não há um consenso do que possa ser conceituado como Arquitetura, sendo para alguns arte e para outros ciência, Zarankin (1999) salienta que estruturas arquitetônicas são freqüentemente encontradas em sítios arqueológicos e estas são tomadas como fontes de informação ou como obstáculo a projetos de escavação. Apontando para uma dialética na produção arquitetônica que confrontaria funcionalidade e arte, Zarankin (1999:120) apresenta o que é denominado como Arqueologia da Arquitetura: "Esta oferece uma nova perspectiva de análise para abordar aspectos relacionados com a confrontação do entorno humano. As construções são vistas como elementos ativos, produtos culturais que interatuam de forma dinâmica com o homem"

Neste texto, Foucault é destacado como um autor que traz aportes para a Arqueologia no sentido de identificar uma Arquitetura atuando como tecnologia do poder. Esta, com sutis estratégias de entrelaçamentos funcionais e construtivos, levaria a uma manipulação da cultura material que visaria moldar indivíduos disciplinados e úteis. Trabalhando com casas da classe média de Buenos Aires, do século XVIII até o presente, Zarankin (1999) buscou estabelecer vinculações e mudanças formais e espaciais entre as casas e o desenvolvimento do sistema capitalista neste tempo e espaço. Além disso, procurou entender como aspectos do cotidiano se moldavam nas transformações arquitetônicas das casas imbricadas no processo de reprodução do capitalismo.

Como conclusão, diz Zarankin: "Neste caso consideramos a conformação morfológico-espacial das casas das classes médias como uma forma de 'auto-disciplinamento' da burguesia, necessária para posteriormente expandir e generalizar esta disciplina para o resto da sociedade e desta forma reproduzir e dar continuidade ao sistema" (op. cit.: 126). 


\section{“Arqueologia do capitalismo: 'estratégias' e 'táticas' na Antártida, século XIX”}

Salientando um recente interesse da Arqueologia em abordar cultura material como fonte de estudo sobre conflito ou raízes sociais do poder, Senatore e Zarankin (2000) utilizam-se dos conceitos de 'estratégia' e 'tática' de Michel de Certeau e os aplicam numa pesquisa arqueológica situada na Antártida, em sítios do século XIX. Trata-se da ocupação por empresas capitalistas que exploravam recursos marinhos através do agenciamento de trabalhadores que, temporariamente, dispersavam-se e se instalavam em pontos espacialmente distintos na paisagem antártica.

A Arqueologia brinda a possibilidade de analisar práticas cotidianas destes indivíduos e discutir sua relação com as estratégias do sistema capitalista. Desta maneira e a partir deste caso se exploram problemas relacionados com a vinculação entre estrutura e ação, aprofundando a análise de contextos particulares em escalas pequenas como parte de um processo maior que é a expansão do sistema capitalista em uma escala global (op. cit.: 106).

\subsection{Arqueologia sul-americana e teorias}

Assunto bastante instigante no debate contemporâneo diz respeito a elaborações teóricas no âmbito latino-americano. Este debate questiona duas situações: é preciso uma teoria arqueológica latino-americana? se não, como trabalhar com Arqueologia na América latina em conjugação com teorias construídas no hemisfério norte?. Os textos a seguir tratam deste debate enfocando os seguintes temas: uma perspectiva para a Arqueologia brasileira; influências do pensamento ocidental e a importância da teoria arqueológica internacional para o caso brasileiro; o questionamento sobre a construção teórica sulamericana e, por fim, um estudo de caso na Arqueologia argentina envolvendo teoria e a primazia do objeto.

\section{"Arqueologia brasileira: uma perspectiva histórica e comparada"}

Convidando os arqueólogos para debaterem sobre uma Arqueologia verdadeiramente nacional, Barreto (1999) mostra que, para este debate, faz-se necessário destacar as especificidades do registro arqueológico e seus contextos como base de escolhas teóricas e metodológicas que visem interpretações e elaborações de tal Arqueologia. Apontando para uma "perspectiva histórica comparativa e crítica para a Arqueologia brasileira, Barreto (1999:203) salienta que é preciso “... explicitar não só as correntes teóricas que influenciaram a produção até hoje e entender como se chegou ao cenário atual de usos de teoria tão pouco explícitos, quase nunca discutidos, e geralmente desprezados na arqueologia brasileira "

Perguntando sobre a Arqueologia brasileira em termos de uma Arqueologia nacional, cuja tarefa seria de resgate e reprodução da cultura nacional, Barreto (1999) responde afirmando que tal proposição ainda não aconteceu em função do isolamento desta Arqueologia em relação aos debates e propostas teóricas internacionais, entre vários fatores. Tal situação adviria de duas constatações: 0 afastamento da Arqueologia brasileira das ciências sociais, principalmente da Antropologia cultural; teorias e metodologias estrangeiras que, em aplicações nacionais, aqui são usadas inadequadamente e descontextualizadas.

Para Barreto (1999) é preciso que a Arqueologia se confronte e busque por um passado cultural visando à construção de uma identidade nacional. A autora faz breves indicações de como esta tarefa vem sendo trabalhada em países como o México e o Peru, dentro da chamada Arqueologia Social. A autora enfatiza a necessidade de uma politização da Arqueologia brasileira em relação ao patrimônio e identidade nacionais, constatando uma ausência: “... numa breve análise da história da arqueologia brasileira no que diz respeito à contribuição da arqueologia para a reconstrução de um passado e identidade nacionais, fica notória a ausência de uma tradição de usos políticos do patrimônio arqueológico." (op. cit.: 207).

O surgimento e construção da Arqueologia no Brasil aconteceram, segundo Barreto (1999) dentro das universidades, porém, sem um projeto curricular e teórico, privado de profissionais treinados e 
especializados. Dada esta situação, intelectuais estrangeiros moldarão e cunharão as inspirações teóricas aplicadas no desenvolvimento da Arqueologia nacional. Serão duas principais influências teóricas que atuarão na Arqueologia brasileira: a Arqueologia francesa e suas missões no Brasil e a Arqueologia norte-americana com a atuação dos arqueólogos Betty Meggers e Clifford Evans.

Preponderantemente conduzida por estas escolas, a Arqueologia brasileira construiu-se mais próxima da História Natural. Ancorando-se na História, manteve-se distanciada das demais ciências sociais, diferentemente da Arqueologia praticada em diversos países da América do Sul. A Arqueologia brasileira vai crescendo isolada das ciências sociais e dos contextos internacionais em termos teóricos. Barreto (1999:208), diante deste quadro, assim conclui: "No Brasil, a arqueologia parece ter ficado soterrada sob a carapaça de uma linguagem técnica desumanizada: fala-se em artefatos, camadas estratigráficas, e sítios arqueológicos, ao invés de culturas, períodos históricos e assentamentos humanos"

\section{"A importância da teoria arqueológica internacional para a Arqueologia sul-america- na: o caso brasileiro"}

"Existe teoria arqueológica no Brasil?" pergunta Funari (1999:213). Existe, porém, com seus pressupostos implícitos ou ocultos. Não estão hermenêutica e ontologicamente explicitados. A teoria na Arqueologia brasileira joga em termos do implícito e do explícito em suas elaborações.

"É possível, no entanto, qualquer trabalho de campo sem teoria?", é outra questão de Funari (1999:213). O autor responde que não é concebível nenhuma atividade arqueológica sem base teórica. O desafio é no sentido de clarear e explicitar as perspectivas e discursos teóricos existentes na prática arqueológica no Brasil.

Relatando sucintamente, Funari (1999) diz que a Arqueologia no Brasil, desde o século passado, vinha sendo conduzida, de um lado, por diretores de museus patrocinados por uma elite $\mathrm{e}$ ligados a um sistema de compadrio e clientelismo dominantes no país. Por outro lado, destaca o autor a figura humanista de Paulo Duarte, propondo a criação de instituições arqueológicas e medidas protecionistas com relação ao patrimônio. Com o golpe militar de 1964, instalase no Brasil um regime de força e de reforço ao compadrio e ao clientelismo. Neste contexto, chegam ao país os arqueólogos norte-americanos Betty Meggers e Clifford Evans, trazendo com eles uma forte predominância positivista e empírica como formação para arqueólogos brasileiros. Porém, de acordo com Funari (1999), diferentemente da aplicação positivista na sociedade norte-americana, no Brasil esta escola foi introduzida num quadro de clientelismo e compadrio gerando práticas não-igualitárias para a produção do conhecimento arqueológico.

Em anos recentes, porém, segundo Funari (1999) este quadro vem mudando devido ao crescente interesse e busca por novas abordagens teóricas e compromissos políticos e sociais que vem tomando a Arqueologia brasileira. $\mathrm{O}$ autor demonstra esta mudança em função da grande produção acadêmica de teses e dissertações e de numerosas publicações e artigos que visam à ampliação dos limites teóricos e políticos, os quais vinham cerceando a Arqueologia praticada no Brasil. Neste sentido, destaca Funari (1999:217) o papel relevante que a teoria traz para o caso brasileiro: "No contexto de uma Arqueologia ainda dominada por relações de compadrio, muitas vezes infensa, até mesmo ao empirismo que busca seguir padrões internacionais de qualidade, a teoria tem um papel crucial em impulsionar os arqueólogos a um pensamento crítico, à interpretação e análise e, não menos importante, a desafiar as idéias e práticas estabelecidas"

\section{"Arqueologia na América do Sul: requer um acercamento especial?"}

Falar de teoria em Arqueologia é falar de prática, prática esta que não deva ser diferente na América do Sul. Para Borrero (2000:193) melhor seria perguntar como "... encarar a investigação arqueológica em geral, não exclusivamente na América do Sul" Questões geográficas serão resolvidas por agendas locais ou regionais. Para Borrero (2000), primeiro é preciso distinguir entre ciência e pseudociência nas construção de agendas científico-políticas e, depois, pensar sobre uma cientificidade da Arqueologia. 
Segundo Borrero, não interessa que uma teoria seja nacional ou sul-americana. O importante é que “... com uma teoria, haveria que se perguntar, [por um lado], que técnicas observacionais esta teoria conduz, [por outro], que instruções dita para recolher materiais. (...) Um esquema assim está capacitado não só para avançar na investigação científica de qualquer lugar, senão também para servir a agendas nacionais ou regionais [para a Arqueologia]." (op. cit.: 196).

\section{"A Arqueologia argentina e a primazia do objeto"}

Tomando como referência a prática arqueológica argentina, na segunda metade do século XX, Nastri (2000) propõe um exame da relevância que vem tomando o conceito de primazia do objeto em tal arqueologia. Este conceito vem sendo orientado por um cientificismo que propugna pela identificação do objeto daquilo que ele é com aquilo que deveria ser. "Desta maneira, entranha uma posição legitimante em relação à ordem social e constitui um dos pilares do isolamento da disciplina arqueológica do resto das ciências sociais." (op. cit.: 117).

Historiografando concisamente a Arqueologia argentina ao longo do século XX, Nastri (2000) aponta as sucessivas concepções teóricas e ideológicas que marcaram a primazia do objeto: renascimento de uma tradição positivista de investigação associada com formulações evolucionistas culturais; difusão de noções de determinismo ecológico; explicações em função de ajustes maximizadores do benefício energético na relação população/ambiente. Nos últimos anos, herdando influências da Arqueologia Processual, a primazia do objeto nas pesquisas vem sendo calcada por explicações que renovaram o marco evolucionista centrando atenção na categoria 'paisagem'. Nesta linha, a primazia do objeto adquire relevância ao apontar para aquilo que perdurou ao invés daquilo que deveria ser. Assim concluí Nastri (2000:119):

O mundo material é parte do homeme não um ambiente externo a ele. (...) Ficar-se aferrado a este feito para reforçar a identidade disciplinar (e os reclames corporativos) ou transcendê-los através de análise cultural, constitui o dilema da Arqueologia frente à primazia do objeto. Implica, portanto, considerar não só questões de índole teórica em torno da concepção do objeto material, senão também levar em conta as determinações políticas e sociais mediadas, fundamentalmente, pela lógica dos campos científicos.

\section{"Influências ocidentais do pensamento arqueológico no Brasil"}

A prática arqueológica no Brasil já tem uma longa trajetória, apesar disto, sugere Funari (2000) que esta prática pode ser encarada como uma invenção ocidental. Por que isto? Desde meados do século XIX, com os trabalhos do dinamarquês Lund e prosseguindo por este mesmo século e até meados do século $\mathrm{XX}$, vários pesquisadores europeus aqui estiveram atuando e incentivando pesquisas arqueológicas. Após a Segunda Guerra, através da atuação de Paulo Duarte, vem da França a principal influência. A partir da década de 1960, muda-se a geografia e vem dos Estados Unidos, através dos arqueólogos Betty Meggers e Clifford Evans o predomínio sobre a Arqueologia brasileira, treinando e formando uma geração de discípulos. Assim sendo, entende-se a sugestão de Funari (2000) de que a Arqueologia no Brasil pode ser entendida como uma invenção ocidental. Dito de outra forma, é impossível desvencilhar a prática arqueológica no Brasil sem estas íntimas e potentes influências. Dentre elas, destaca o autor a chamada escola Histórico-Cultural, um "modelo ubíquo"

A prática arqueológica deve ser entendida como uma prática que encare a Arqueologia como um processo social e material (Funari 2000). Esta assertiva é particularmente importante e bastante problemática quando se estuda as influências da escola Histórico-Cultural que vem, de longa data, afirmando que nacionalidade é a identificação de uma linguagem, uma raça, uma cultura. Para a América do Sul, onde é possível identificar vários grupos étnicos, ligados por supostas bases linguiísticas, agrupados em dados da cultura material dentro de uma homogeneidade, a trilogia acima mostrada, advinda do histórico-culturalismo, mostra-se como uma fácil influência a ser identificada no registro arqueológico. Apontando alguns estudos em vários países latinos onde este predomínio teórico 
acontece, para o Brasil, destaca Funari (2000) o caso da chamada Tradição [arqueologicamente definida] Tupiguarani. Citando vários exemplos, esta ubiqüidade de uma linguagem, uma raça e uma cultura, vem sendo peremptoriamente aplicada nas pesquisas arqueológicas envolvidas com tal tradição, principalmente com o uso da cerâmica $e$ tomando-a como uma uniformidade nas pesquisas realizadas no âmbito da Arqueologia brasileira.

Conclui Funari (2000) que este ubíquo modelo de influência ocidental ainda oferece substanciais atrações nas elaborações teórico-metodológicas praticadas na Arqueologia brasileira. Por outro lado, salienta o autor que a predominância deste modelo vem sofrendo desafios pelos questionamentos advindos de novas gerações de arqueólogos brasileiros e suas conexões com outras propostas no âmbito da arqueologia mundial.

\subsection{Patrimônio e cultura material, teorizações}

Este tema vem provocando incômodos na prática arqueológica. Desconfortos, pois divulgar e refletir sobre o patrimônio arqueológico, sustentado pela cultura material exumada e pesquisada, implica em trazer para a Arqueologia posições e ações políticas em termos sociais. Implica em atuar com cidadania, pertencimento, memória. Tirar do isolamento acadêmico e das mudas exposições nos museus o que vem sendo trabalhado na pesquisa arqueológica.

\section{"Museu, Educação e Arqueologia: prospecções entre teoria e prática"}

Museu, Educação e Arqueologia estão dissociados e estranhos como conjunto no que possa compor um currículo escolar no Brasil. Estas instâncias, porém, compõem um instrumental que tem íntima conexão com o processo de humanização, conforme destaca Tamanini (1999). É imbricando este processo com o tema que Tamanini (1999) traz Foucault, que se refere a nossa infância sapiencial em termos de apenas 100 mil anos como homo sapiens.

Educação e passado se conjuminam obrigatoriamente ao se tratar de hominização, herança cultural e patrimônio arqueológico quando "...a memória social ou coletiva, evidenciada a partir dos registros, vestígios ou fragmentos, considerados conceitualmente como bens culturais de uma dada sociedade, constitui-se em referencial de identidade cultural e instrumento mediador entre sujeito histórico e cidadania" (op. cit.: 340). Aqui são apontados evidentes pressupostos que implicam na atuação política e social da Arqueologia. Porém, de acordo com Tamanini (1999), devido a nossa controversa tradição democrática, discussões sobre Educação e Arqueologia são bastante recentes. Outro aspecto destacado diz respeito à relação entre Museu e Arqueologia. Para Tamanini (1999) esta relação está comprometida e obstaculizada ainda pelos seguintes fatores: os arqueólogos desconhecem o potencial de democratização do conhecimento construído com o trabalho museológico sobre a cultura material das coleções; os bens preservados têm sido enfatizados em torno de bens produzidos pelas elites; a preservação tem destacado temas de saudosismo e de exotismo distantes da realidade próxima do cidadão em relação aos bens preservados.

Trazendo estes aspectos para uma experiência e atuação, Tamanini (1999) relata o trabalho de educação patrimonial que vem sendo realizado no Museu Arqueológico de Sambaqui de Joinville/SC. Para a autora, a experiência de um museu local, trabalhando em termos de uma atuação política e democrática, enfrenta obstáculos assentados por “... classes dominantes que decidem o que deve ser lembrado e esquecido de acordo com seus desejos e interesses e não de acordo com a realidade histórica de cada grupo que constitui a sociedade" (op. cit.: 342). Este confronto aponta para o desafio de uma educação patrimonial que envolva Arqueologia e Museu em termos de se construire atuar na criação de uma cidadania plena.

\section{"Teoria arqueológica, cidadania e prática profissional em Buenos Aires"}

"Na cidade de Buenos Aires a teoria arqueológica se situa bastante atrás, num lugar de menos importância, sendo avassalada por uma prática institucional que bem poderia ser significada como um escudo com uma plaina e um serrote ", conforme aponta Wiessel (2000:170).

Para o autor, esta prática institucional reage contra compromissos que envolveriam uma prática 
social e política da Arqueologia em relação a conflitos sociais. Falar de cidadania e sua relação com patrimônio arqueológico conjuga crítica e ação em diferentes escalas relacionadas a conflitos sociais, bem como, à clara e explícita formulação teórica.

Weissel pergunta como é possível uma prática profissional arqueológica que conjugue aspectos acadêmicos e políticos em termos de cidadania e pertencimento? Responde que:

Cidadania relacionada a Arqueologia compreende a constituição de valores sobre o que se entende por patrimônio arqueológico no marco de projetos sociais específicos e locais, como pontos de referências e compromissos de caráter transversal por parte dos atores envolvidos (op. cit.: 169).

\section{Amarrando}

Bem, aqui estão alguns dos textos inseridos no conjunto dos trabalhos apresentados nas duas reuniões internacionais de teoria arqueológica. Pelo sim e pelo não que ainda titubeia neste tema pelos fazeres arqueológicos brasileiros, em termos de desprezo ou indiferença com relação ao lugar da teoria, é uma situação anacrônica, diante da importância já sedimentada pelos textos aqui apresentados. Por este viés, observo que no Brasil não se pode mais falar de resistência à teoria, mas a novas abordagens teóricas. O relevante é, como aponta Yofee (1996:108): "A questão, portanto, não é, devem os arqueólogos ser teóricos, mas qual a teoria boa e apropriada"

Assim sendo, tratar de teoria na Arqueologia é ainda uma tarefa semelhante à de cortar cebola. De camada em camada, talha-se com o fito de dar sabor ao prato, porém ao custo de lágrimas provocadas. Nesta tarefa, a importância fundamental está naquela fina e transparente película que separa as brancas e suculentas túnicas carnosas da cebola. Estas, podem ser comparadas às construções e aportes teóricos para o prato saboroso do fazer arqueológico. Já estão postos e sedimentados a partir do que foi aqui glosado dos textos das reuniões. As lágrimas no trinchar ainda são advindas da fina película transparente, porém marcadora de fronteira entre as aplicações dos tantos caminhos teóricos que a transdisciplinaridade aborda de forma inexorável em portos da teoria para a Arqueologia.

A transdisciplinaridade: trânsito, transa, troca. Parte-se sempre de um ramo do vasto campo científico. Esta partida marca o pensar. Para construir idéias, com métodos e técnicas que sejam, é deste início pensante que se darão. A transdisciplinaridade visa a produção integradora de conhecimento, não a formação de blocos informacionais, engordados pelos suculentos conjuntos obtidos nas pescas pelas disciplinas todas percorridas. Traz desafios sobre os caminhos de pensar e repensar constantemente qualquer fazer científico. "A transdisciplinaridade, como movimento de transformação das ciências, abertura para o social, o estético e o ético, não nascerá espontaneamente. (...) Seu aprofundamento implica um permanente pesquisar sobre a pesquisa" (Guattari 1991:11).

1. Estes caminhos trandisciplinares estão suficientemente demonstrados pelos trabalhos das duas reuniões teóricas internacionais. Thomas (1999) volta à era moderna para uma caracterização da Arqueologia. Esta volta está hoje bastante perturbada e turbulenta por todos os questionamentos que vem sofrendo o projeto moderno (Bauman 1999). Mas, mesmo ao caracterizar a Arqueologia dentro da modernidade, salienta Thomas (1999) que o estudo da cultura material para a Arqueologia é um enfoque que provoca mudança do estudo de entidades para o estudo de relações. Aqui posso encontrar um paralelo com a proposta de Orser (1999) ao trazer a teoria da rede para a Arqueologia, destacando as inter-relações entre homens e mulheres na produção e reprodução da vida social.

Aventa-se, mesmo que através da ironia e da perplexidade, se é possível juntar Foucault com Arqueologia. Não só é possível como plausível, a partir das referências, poucas porém, que se manifestaram vindas dos autores aqui apresentados. O primeiro deles é o de Thomas (1999) que traz Foucault e o tema do poder em termos de vida social expressada na cultura material. Aliás, é o tema do poder que também vai estar presente em outra referência através de teorias arqueológicas (Zarankin 1999). Para o primeiro, a cultura material encarada como um dos efeitos do poder na vida social, para o segundo, a identificação dentro da denominada Arqueologia da Arquitetura de uma tecnologia do poder. A partir deste tema do poder e com as referências acima apresentadas, fica 
bastante claro que não há obstáculo maior em se buscar aportes no pensamento de Foucault para a Arqueologia. Neste sentido, encontra-se o seguinte neste pensador: "Neste nível, não se trata de saber qual é o poder que age do exterior sobre a ciência, mas que efeitos de poder circulam entre os enunciados científicos; qual é seu regime interior de poder; como e por que em certos momentos ele se modifica de forma global" (Foucault 1979:4).

2. Saindo do tema do poder e Foucault, dirijome a possíveis abordagens da Filosofia sobre a Arqueologia. Entra-se num terreno ainda espinhoso e muito instigante. Tanto a Arqueologia Processual, a partir de postulados da Filosofia da Ciência, como a Arqueologia Pós-Processual, a partir de postulados da Hermenêutica, do Estruturalismo, da Teoria Crítica, do Marxismo, entre tantos outros, trouxeram de forma contundente a Filosofia para dentro da Arqueologia. Trigger (1998) apresenta Robin Collingwood como sendo, talvez, o primeiro filósofo e também arqueólogo que envidou esforços para se entender o passado aliado a uma busca sobre a natureza do pensamento humano, tomando como base investigações filosóficas. Quanto à Hermenêutica para a Arqueologia, salientam Johsen e Olsen (1992:420): "O âmbito da filosofia hermenêutica cruza com um ponto fundamental na epistemologia da arqueologia: Quais são as (pré)condições para nosso entendimento da sociedade humana do passado? A questão hermenêutica é não só o que entendemos quanto como entendemos: que condições fazem entendimento desta variedade possível entre passado e presente?"

Aportes filosóficos já chegaram à Arqueologia brasileira. Trata-se do trabalho de Magalhães (1993) que, buscando achegas em Kant, Foucault, Baudrillard, Deleuze, entre outros, pergunta sobre uma possível confusão que a Arqueologia vem fazendo ao colocar a categoria tempo como mudança ou como manifestação primeira. Como resposta, o autor propõe ".... discutir o conceito de origem, que vem sendo relacionado ao conceito de tempo como manifestação primeira e o conceito de gênese, confundido com o primeiro mais, indiretamente, o conceito de mudança" (Magalhães, 1993:11). É nesta verve que Karlsson (1999) pergunta por cultura material e pelo nada, tendo por escopo provocar reflexões filosóficas num pensar múltiplo que guia e funda teoria na Arqueologia.
Numa Arqueologia praticada no Brasil com desdém por teoria, perguntar por cultura material em vez de nada, questionar por Existência e existência e interrogar sobre a categoria tempo, deve causar embrulhos nos estômagos abarrotados de velhas práticas empíricas sobre sítios, poçostestes, níveis artificiais e sobre contagens mecânicas de cacos e cacos exumados numa nomeada tal cientificidade exclusiva de verdade.

\section{Já falei sobre poder, sobre Filosofia.} Continuo cortando a cebola da teoria em Arqueologia, sempre destacando as interfaces representadas por aquela tênue e transparente película que separa as camadas, os aportes teóricos que vão compondo um todo transdisciplinar no fazer arqueológico.

Este fazer vem sendo perturbado por mudanças em concepções teóricas várias, conforme o que foi apresentado na $I^{\mathrm{a}}$ e II ${ }^{\mathrm{a}}$ RITAAS. Consens (2000) enfatizou as consequêencias que estas mudanças teóricas vêm provocando e sobre os tantos 'ismos' que se seguem como sobrenomes da Arqueologia. Esta tem vários sobrenomes. Procuram por uma possível identidade num pormenor de jogo de linguagem que a podem configurar em lugares socialmente reconhecidos pelo terreno da academia, quais sejam: histórica, pré-histórica, histórico-cultural, marxista, de contato, da paisagem, contemplativa, processual, subaquática, pósprocessualista, etnoarqueologia, nova arqueologia. Fica sempre a Arqueologia mais um sobrenome que diga de que lugar é, de quais técnicas se trata e com que métodos atua. Sobre estes sobrenomes e 'ismos', Faria (1989) aponta para 'dependência' 'insegurança' e 'renúncia' que permeariam o estranho caminho da Arqueologia brasileira. Sobre esta, diz o autor que “... a arqueologia deixa-se ficar numa posição subordinada, arrimando-se na botânica, na zoologia, na ecologia, na geologia, na geografia, das quais pretende, ingenuamente, auferir sua cientificidade" (op. cit.: 32). Fica, deste modo, reservado um papel preponderante para métodos $\mathrm{e}$ técnicas que se confundem com teoria, numa submissão interdisciplinar de não-identidade, pela qual vem trilhando a Arqueologia brasileira.

O que sugere uma submissão interdisciplinar de não-identidade? Não mais que modismos da academia. Num sufoco de tantas fragmentações em que o conhecimentoé panorama, a interdisciplinaridade vem dar alerta e propor fusões, trocas e, finalmen- 
te, que se aceite a interdependência que sempre circulou e constituiu o todo do conhecimento produzido pelo ser humano. A interdisciplinaridade como formadora de blocos informacionais, engordados pelos suculentos conjuntos obtidos nas pescas pelas disciplinas todas percorridas. Neste sentido, Althusser (1979) fala da interdisciplinaridade como um mito nas ciências humanas. Como uma prática de pedir emprestado noções, conceitos e métodos às tantas disciplinas que compõem os níveis do campo científico. Assim, diz Althusser (1979:50):

É a prática eclética das "mesas redondas" interdisciplinares. Convidam-se os vizinhos, ao acaso, melhor ou pior, para não esquecer ninguém, nunca se sabe. Quando se convida toda a gente, para não esquecer ninguém, isto significa que não se sabe ao certo quem convidar, que não se sabe onde se está, que não se sabe para onde se vai. Esta prática das "mesas redondas" duplica-se necessariamente numa ideologia das virtudes da interdisciplinaridade, que é o contraponto e a missa. Esta ideologia encerra-se numa fórmula: quando se ignora qualquer coisa que toda gente ignora, basta reunir todo os ignorantes: a ciência sairá da reunião dos ignorantes.

Não é apenas desta submissão interdisciplinar de não-identidade que se poderia ressaltar o que Consens (2000) destaca quanto aos 'ismos' e sobrenomes da Arqueologia. Segundo este, uma busca de poder pessoal e institucional os permearia também, no âmbito da produção do conhecimento. Neste sentido, destaca-se o que Foucault (1984:30) fala sobre este jogo de poder pessoal e institucional, de poder-saber na academia: “... não é a atividade do sujeito do conhecimento que produziria um saber, útil ou arredio ao poder, mas o poder-saber, os processos e as lutas que o atravessam e que o constituem, que determinam as formas e os campos possíveis do conhecimento"

4. Arqueologia existe para isto também: para alguns, construção de passados; para outros, reconstrução de passados. Zarankin (2000) demonstra que esta dualidade se apresenta em duas importantes correntes teóricas na Arqueologia: a processual conjuga-se ao pensamento moderno e a pós-processual açambarca os múltiplos caminhos dos pensamentos pós-modernos.

Para Binford (1994), dentro do marco processual, o arqueólogo não é um descobridor do passado, pois este está aqui, no presente. As atividades humanas são compreendidas dentro de uma categoria dinâmica, já extinta, porém presentificada como vestígios materiais dentro de uma categoria estática. “... o desafio que a Arqueologia propõe consiste na transcrição, de maneira literal, da informação estática contida nos restos materiais observáveis para reconstruir a dinâmica da vida no passado e estudar as condições que tornaram possível que estes materiais tenham sobrevivido e chegado até nós" (op. cit.: 24). Traçando um panorama crítico dos principais postulados do processualismo, Bayard (1983) aponta que um dos problemas desta escola é encarar os feitos humanos e os processos culturais do passado como sendo reais e empiricamente observáveis dentro desta dualidade de dinâmica/ estática em relação aos vestígios materiais.

O passado no pós-processualismo é encarado por Hodder (1994) como tendo uma base social contemporânea para as possíveis reconstruções. Estas reconstruções estarão imbuídas nas influências, nos pré-juízos atuais, oriundos do contexto social, político, ideológico e econômico de onde atua o arqueólogo. Passado e presente estabelecem uma relação dialética: o passado interpretado em função do presente; o passado utilizado para se criticar e desafiar o presente. "Por isso a Arqueologia Pós-processual é simplesmente 'pós'. Parte de uma crítica do anterior, construindo sobre essa via, porém, ao mesmo tempo, divergindo dela. Supõe diversidade e falta de consenso. Caracteriza-se pelo debate e a incerteza acerca dos problemas fundamentais pouco discutidos anteriormente em Arqueologia. É mais uma proposição de perguntas do que uma provisão de respostas" (op. cit.: 190). Além desta dialética, o pós-processualismo advoga pela não existência de um único passado, mas de vários, construídos de diferentes lugares a partir dos arqueólogos que o pesquisam, das descontinuidades, das rupturas, dos recortes, das construções discursivas que compõem estes diversos passados (Foucault 1995, 1998).

\section{As discordâncias teóricas poderão advir} desta possível 'dialética' entre passado e presente. Um consenso atual, porém, firma-se cada vez mais 
sobre o postulado de que não se trabalha mais com um único e real passado a ser desvendado, construído ou reconstruído. São vários e múltiplos, assim como são matizados os lugares de olhar para os mesmos e diferentes passados (Gumbrecht 1999). A proposta de Orser (1999) pode ser encarada dentro destes aspectos de muitos passados trabalhados através das inter-relações que homens e mulheres estabelecem ao atuarem na produção e reprodução da vida social. Estas interrelações estabelecidas como redes, como teias, desfazem as idéias de se buscar por um passado único, real e monolítico. Deleuze e Guattari (1980) propõem, contra esta monolitização enraizada de um verdadeiro passado, o "rizoma" [rede, teia].

Algumas das características do "rizoma" apontadas pelos autores (op. cit.: 32-33) trazem uma adequação para estas múltiplas construções/re-construções de passados: “... diferentemente das árvores ou de suas raízes, o rizoma conecta um ponto qualquer com outro ponto qualquer e cada um dos seus traços não remete necessariamente a traços de mesma natureza; (...) ... o rizoma se refere a um mapa que deve ser produzido, construído, sempre desmontável, conectável, reversível, modificável, com múltiplas entradas e saídas, com suas linhas de fuga". A rede, a teia de inter-relações a serem explanadas a partir de passados como um rizoma de interligações e múltiplas interpretações.

Assim, concluo esta amarração por entre os diversos textos apresentados e oriundos das duas reuniões internacionais de teoria arqueológica. A partir do que acima foi traçado, pode-se constatar que o fazer arqueológico não pode mais prescindir de teorias (Hodder 2001). Estas se apresentam concretamente à Arqueologia e faz-se necessária apenas a demanda dos arqueólogos em busca de suas rizomáticas e transdisciplinares possibilidades. Para o possível lugar da teoria na Arqueologia brasileira, a demanda acima apontada é ainda motivo de indefinições, de resistências. As práticas de campo com os métodos e técnicas já bem conhecidos e desenvolvidos e as análises quantitativas e descritivas nos laboratórios, pontuam os limites, em relação a teorias, que mapeiam a pesquisa arqueológica no Brasil. Nas publicações, em sua grande maioria, os marcos teóricos permanecem tênues ou ocultos. No Brasil, na maioria dos resultados das pesquisas em Arqueolo- gia, permanece ainda uma resistência à teoria. Os textos publicados sugerem como se fosse mesmo desnecessário marcar teorias ou elas estão veladas, ocultadas em um proposital mascaramento de inexistência. Tais constatações apontam para um equivocado entendimento do rigor científico da pesquisa arqueológica no Brasil como prescindindo de postulados teóricos. Pode-se caracterizar não tanto "resistência" mas aderência velada a correntes teóricas, imprescindíveis em qualquer fazer científico e produtor de conhecimento, lugar inegável da Arqueologia. É possível, portanto, perguntar-se e investigar sobre o lugar da teoria na Arqueologia brasileira. É inconteste sua existência. O que precisa ser feito é um desvelamento que explicite o que já existe implícito ou oculto. Fundamentar um esclarecimento sobre qual ou quais teorias estão sendo aplicadas e usadas nas pesquisas arqueológicas. Esta constatação aponta para uma hipótese: a Arqueologia brasileira já possui um corpus teórico, posto que fragmentado, disperso ou oculto nos textos publicados. Pelo exposto acima e pelas várias possibilidades de se trabalhar com teoria na Arqueologia, assunto demonstrado na proposta deste texto, fica claro que é possível que ocorra na Arqueologia brasileira o que poderá ser um proposital velamento, reforçador de descritivismos e dados empíricos, em detrimento de um assumir teórico e conceitualmente explícito.

Com relação a este desafio para a Arqueologia e os múltiplos passados a serem interpretados, concorda-se com o que diz Tesche (2000:19): “... em geral não se conhece senão o que já se sabe, mas ou se esqueceu ou ainda não se encontrou a maneira de dizê-lo. (...) ... rememorar o que, no fundo, já se sabe e dizer quanto se queria, mas não se logrou dizer"

\section{Agradecimentos}

Este texto faz parte das pesquisas que venho desenvolvendo no âmbito da tese de doutorado que tratará das condições de possibilidade da teoria na Arqueologia brasileira. Assim, meus agradecimentos ao orientador, Prof. Dr. Pedro Paulo Abreu Funari e ao auxílio financeiro da FAPESP. Também ao colega Lucio Meneses Ferreira e à companheira e arqueóloga Fernanda Bordin Tocchetto. 


\section{Referências bibliográficas}

AGUIRRE, D.D.

2000 Pasos preliminares para la construcción de un modelo sistemico-procesual-dialectico. Livro de Resumos - II Reunión Internacional de Teoria Arqueológica en América del Sur. Olavarria, UNCPBA: 94-97.

ALTHUSSER, L.

1979 Filosofia e filosofia espontânea dos cientistas. Lisboa: Presença.

ARAUJO, A.G.M.

1999 As Geociências e suas implicações em teoria e métodos arqueológicos.

M.I.D. Fleming (Ed.) Anais da I Reunião Internacional de Teoria Arqueológica na América do Sul. Revista do Museu de Arqueologia e Etnologia, Suplemento 3, São Paulo: 35-45.

BARRETO, C

1999 Arqueologia brasileira: uma perspectiva histórica e comparada. M.I.D. Fleming (Ed.) Anais da I Reunião Internacional de Teoria Arqueológica na América do Sul. Revista do Museu de Arqueologia e Etnologia, Suplemento 3, São Paulo: 201-212.

BAUMAN, Z.

1999 Modernidade e ambivalência. Rio de Janeiro: Jorge Zahar.

BAYARD, D.

1983 La "Nueva Arqueologia": una historia crítica. Scripta Ethnologica, suplementa 2: 9-27.

\section{BINFORD, L.}

1994 En busca del pasado. Barcelona: Crítica. BORRERO,L.A.

2000 Arqueologia en América del Sur. Se requiere un acercamiento especial?

Livro de Resumos - II Reunión Internacional de Teoria Arqueológica en América del Sur. Olavarria, UNCPBA: 193-196.

CONSENS, $\mathrm{M}$.

2000 Teoria para el conocimiento, o teorias para la "fijación de creencias". Livro de Resumos - II Reunión Internacional de Teoria Arqueológica en América del Sur. Olavarria, UNCPBA: 98-101.

DELEUZE, G.; GUATTARI, F.

1980 Mil platôs - capitalismo e esquizofrenia. Volume 1, São Paulo: Ed. 34.

FARIA, L.C.

1989 Domínios e fronteiras do saber: a identidade da Arqueologia. Dédalo, Suplemento I, São Paulo: 26-39.

FLAMMARION, C.

1979 Narrações do infinito. Rio de Janeiro: FEB. [1866]

FOUCAULT, M.

1979 Microfísica do poder. Rio de Janeiro: Graal.

1984 Vigiar e Punir. Petrópolis: Vozes.
1995 A arqueologia do saber: Rio de Janeiro: Forense Universitária.

1998 A ordem do discurso. São Paulo: Loyola. FLEMING, M.I.D. (Ed.)

1999 Anais da I Reunião Internacional de Teoria Arqueológica na América do Sul. São Paulo, Revista do Museu de Arqueologia e Etnologia, Suplemento 3, São Paulo.

FUNARI, P.P.A.; NEVES, E.G.; PODGORNY, I.

1999 Introdução - a primeira reunião internacional de teoria arqueológica na América do Sul : questōes e debates. M.I.D. Fleming (Ed.) Anais da I Reunião Internacional de Teoria Arqueológica na América do Sul. Revista do Museu de Arqueologia e Etnologia, Suplemento 3, São Paulo: 1-12.

FUNARI, P.P.A

1999 A importância da teoria arqueológica internacional para a Arqueologia sul-americana: o caso brasileiro. M.I.D. Fleming (Ed.) Anais da I Reunião Internacional de Teoria Arqueológica na América do Sul. Revista do Museu de Arqueologia e Etnologia, Suplemento 3, São Paulo: 213-220.

2000 Influências ocidentais do pensamento arqueológico no Brasil. Livro de Resumos - II Reunión Internacional de Teoria Arqueológica en América del Sur. Olavarria, UNCPBA: 72-74.

GUATTARI, F.

1991 Fondaments ethico-politiques de l'interdisciplinarité. Unesco: Avril.

\section{GUMBRECHT, H.U.}

1999 Em 1926 - vivendo no limite do tempo. Rio de Janeiro: Record.

HODDER, I.

2001 Archaeological theory today. Cambridge: Polity.

1994 Interpretación en arqueología - corrientes actuales. Barcelona: Crítica.

JOHSEN, H.; OLSEN, B.

1992 Hermeneutics and archaeology on the philosophy of contextual archaeology. American Antiquity, 54 (3): 419-436.

KARLSSON, $\mathrm{H}$

1999 Por que há cultura material ao invés de nada? Uma questão esquecida da Arqueologia. M.I.D. Fleming (Ed.) Anais da I Reunião Internacional de Teoria Arqueológica na América do Sul. Revista do Museu de Arqueologia e Etnologia, Suplemento 3, São Paulo: 21-29.

MAGALHÃES, M.P.

1993 Tempo arqueológico. Belém, Museu Paraense Emilio Goeldi.

NASTRI, $X$.

2000 La Arqueologia Argentina y la primacia del objeto. Livro de Resumos - II Reunión 
Internacional de Teoria Arqueológica en ORSER Jr., C.E.

América del Sur. Olavarria, UNCPBA: 117-119.

1999 A teoria de rede e a Arqueologia da História Moderna. M.I.D. Fleming (Ed.) Anais da I Reunião Internacional de Teoria Arqueológica na América do Sul. Revista do Museu de Arqueologia e Etnologia, Suplemento 3, São Paulo: 97-101.

SENATORE, M.X.; ZARANKIN, A.

2000 Arqueologia del capitalismo: "estrategias" y "tacticas" en Antártida, siglo XIX. Livro de Resumos - II Reunión Internacional de Teoria Arqueológica en América del Sur. Olavarria, UNCPBA: 105-106.

TAMANINI, E.

1999 Museu, Educação e Arqueologia: prospecções entre teoria e prática. M.I.D. Fleming (Ed.) Anais da I Reunião Internacional de Teoria Arqueológica na América do Sul. Revista do Museu de Arqueologia e Etnologia, Suplemento 3, São Paulo: 339 345.

TESCHE, A.

2000 Interpretação - rupturas e continuidades. São Leopoldo, UNISINOS.

THOMAS, J.

1999 A materialidade e o social. M.I.D. Fleming (Ed.) Anais da I Reunião Internacional de Teoria Arqueológica na América do Sul. Revista do Museu de Arqueologia e Etnologia, Suplemento 3, São Paulo: 15-20.
TRIGGER, B.

1998 Archaeology and epistemology: dialoguing across the Darwinian chasm. American Journal of Archaeology, 102: 1-34.

VELANDIA, C.

2000 Anti-Hodder: diatriba contra las veleidades post-modernistas en el post procesualismo de Ian Hodder. Livro de Resumos - II Reunión Internacional de Teoria Arqueológica en América del Sur. Olavarria, UNCPBA: 133-134.

WEISSEL, $M$.

2000 Teoria arqueológica, ciudadanía y practica profesional en Buenos Aires. Livro de Resumos - II Reunión Internacional de Teoria Arqueológica en América del Sur. Olavarria, UNCPBA: 169-170.

YOFEE, N

1996 Teoria social e evolucionista e seus descontentes. Anais da VII Reunião Científica da Sociedade de Arqueologia Brasileira, volume I, Porto Alegre, EDIPUCRS: 47-81.

ZARANKIN, A.

1999 A Arqueologia da Arquitetura: another brick in the wall. M.I.D. Fleming (Ed.) Anais da I Reunião Internacional de Teoria Arqueológica na América do Sul. Revista do Museu de Arqueologia e Etnologia, Suplemento 3, São Paulo: 119-128.

2000 La construcción del pasado en Arqueologia. Livro de Resumos - II Reunión Internacional de Teoria Arqueológica en América del Sur. Olavarria, UNCPBA: 102-105. 